\title{
Self-service Reference and Consultation Mode of University Library Based on Micro Video and New Media
}

\author{
Kang Enting ${ }^{*}$, Zhou Xiaolan \\ North China Electric Power University, Baoding, Hebei, China \\ kangenting@163.com
}

\begin{abstract}
Keywords: Micro-Video Course; New Media; University Library; Reference and Consultation; Self-help
\end{abstract}

\begin{abstract}
According to the needs of the reader's personalized consultation, a self-help reference and consultation system is constructed based on micro-video courses and new media methods. The system consists of "micro-video Q \& A classroom", resource navigation, Advisory website, QQ group and other real-time consulting methods.
\end{abstract}

\section{Introduction}

With the development of information technology, library electronic resources are increasingly rich, knowledge management methods are also progressing, the library for the reader's information literacy education and reference work has become more important. Reference and consultation covers more and more content, not only more information on database resources, but also guidance to use a variety of software, such as the use of literature management software and its function on paper writing, knowledge and notes management tools and so on.

The current reference service has faced some problems as follows. The demands of readers in different stages and levels tend to diversify and personalized, the traditional consultation method has been difficult to fully meet the changing needs of the reader. For the common problems in telephone consultation, consulting librarians face with a lot of duplication of work. For the questions on using of the software or webpage operation, the telephone communication is difficult to explain clearly, and need the readers to come to the library to consult the librarians face to face. The consulting efficiency and access to services is less convenient.

With the emergence of micro-video courses and the rapid development of new media technology, the popularity of online learning and mobile learning has greatly influenced the reader's learning habits, and also provided the opportunity and technical support for the library to develop new reference and consultation model.

\section{Micro-video and new media technology application status}

2.1 micro-video and micro-video courses. Micro-video refers to the video with durations of 30 seconds to 20 minutes, such as video clips, advertising clips, etc. [1]. Micro-video has the characteristics of easy transmission and downloading, which facilitates learners to use mobile devices to carry out mobile learning anytime and anywhere using fragmented time [2]. In view of the above advantages, the university libraries carry out the micro-video and micro-video courses recently. Micro-video applications in the library include services to library admission education and training, database resource training [3]. The author has been engaged in retrieval course teaching and information consultation for years. Combined with the practical problems, the author thinks that the micro-video course is suitable for the library for consultation Q \& A service, which has been verified through the practice in the library of the North China Electric Power University (referred as "our library" below).

2.2 New media technology. The academia has been controversial with the concept of "new media" [4,5]. There are two main thought, respectively, from the "new media" features, or its connotation and extension of the definition of "new media" concept [6]. 
Professor Xiong Chengyu defined the new media from the feature. He pointed out that the so-called new media is a concept relative to the old, today we are talking about new media usually refers to the computer information processing technology based on the emergence and impact of media forms. It is also pointed out that it is a concept of development. With the development of science and technology, the media form is also developing, and other new media forms may appear after the present digital media [7].

Jiang Hong and $\mathrm{Xu}$ Jian define the new media from the connotation and extension of two aspects. The new media can be seen as media Based on the digital technology makes the dissemination of information greatly expanded, greatly accelerated the speed of transmission, enriched the mode of transmission greatly, and was quite different from the traditional media. In terms of its extension, new media mainly include optical fiber cable communication network, urban two-way transmission cable television network, computer communication network, large computer database communication system, communication satellite and satellite television system, The Internet, mobile text messaging and multimedia information interactive platform, multimedia technology and the use of digital technology broadcast network [8]. Some researchers pointed out that the current new media include the Internet and mobile media, because only the two have a real interaction [4].

In summary, we can think of "new media" is a new form of media refers to the traditional media with faster transmission, richer way of transmission based on digital technology, mainly for the Internet and mobile media. Mobile phones, tablet PCs, IPAD and other mobile terminals are becoming the main tool of the network. The current readers, are highly dependent on the above new media approach to solve their problem, Library reader services should also follow the trend and try new media technology.

\section{Self-service reference and consultation system of university library based on the micro-video curriculum and new media technology}

On the basis of resources navigation, web information desk and academic service, our library has guided the reader self-learning and self-help learning by using micro-video and new media technology. A "micro video online Q \& A" network classroom was developed to encourage readers to self-study online. New media channels are used for pushing "personal customization" training courses, embedded teaching and other personalized Academic services.

3.1 Micro-video online $\mathbf{Q} \& \mathbf{A}$ classroom. A "micro-video online Q \& A" classroom section is set up on Library website in order to solve the common problems during using digital resources, which are difficult to make clear answers in the phone. The video of Q \& A is produced in the form of micro-video, which can be browsed on the library website and public channel. The content of the micro-video includes the specific database retrieval techniques, document management software application, and how to use the literature management software to assist the thesis writing. Through the micro-video, the reader can learn and understand easily. Micro-video are recorded by the consulting librarian with the way the screen recording video with free software "screen recording expert", editing with video editing software of WINDOWS 10 system. The entire production process without additional financial and personnel training costs, easy to promote the implementation.

"Micro-video online Q \& A" classroom has the following advantages:

(1) Vivid: operation while explaining, easy to understand.

(2) Clear theme: the content of small size and signal theme, easy to learn and absorb; help to meet personalized consulting needs.

(3) Short: each video is one to ten minutes longs, most two or three minutes, suitable for the use of fragmented time to learn.

(4) Multi-channel release, being convenient for readers to learn: through the library website and WeChat release, readers can browse online through a web browser or mobile phone.

(5) The production of simple, low cost: video productions are recorded and edited by the librarian with free software, no additional cost, can easily update or expand the content. 
(6) Reduce the burden of the consulting librarians, and greatly facilitate the reader, reducing the psychological burden of the reader: the reader does not understand the problem, they can repeatedly watch micro-video without worrying about increasing the work of the consulting librarian.

While enriching our own micro-video education resources, we also explore the feasibility of integrating online video education resources, such as NoteExpress series video, and other database providers release video learning resources. Through the integration of resources, making micro-video content richer, provide readers with more convenient access to information.

"Micro-video online Q \& A" is like a librarian beyond the time and space, anytime, anywhere for readers to answer their questions. It's welcomed by readers, and has been clicked and played more than a thousand times just over a month.

3.2 new media ways. Make full use of websites, blog, QQ, WeChat and other new media channels, to provide readers with personalized service. In order to facilitate readers from time and place restrictions on the use of laptops, smart phones, tablet PCs and other mobile terminal networking learning, the library building also achieved WIFI full coverage.

Through the library website, "science and technology information retrieval course network teaching platform", Wechat and other means, to provide digital resource use guide, retrieval course teaching courseware, admission education courseware and other teaching resources download, and collected more than sixty databases of the various libraries of the official use of the guide to download, so that readers can more easily get the electronic resources guidance.

Academic librarians have set up QQ group, teacher blog, etc., to establish new media interaction platform with readers, reply to the reader consultation online, push information about electronic resources and the "private custom" lecture.

3.3 Characteristics. It can reduce the work intensity of the library and better meet the needs of the students by means of new media methods, such as library website, WeChat platform, QQ real-time online academic service, teaching website, teacher's blog and so on. Improve reader's learning interest and learning efficiency. The content from shallow to deep, including the knowledge on library and digital resources, database retrieval skills, the application of document management software, as well as paper writing and publication selection guide, to meet the needs of different stages of academic research. Combined with private customized lectures, embedded courses and other personalized academic services, the self-help, multi-level, multi-channel, cross-space reference and consultation system is formed for undergraduate, graduate students and teachers.

\section{Summary}

The development of self-service reference and consultation system based on micro-video and new media technology enables readers at different levels to obtain the necessary consulting services by means of new media, and provide various kinds of online and offline academic services. It also extends the library service space, expands the library service channel. The reference and consultation service of breakthrough time and space restriction, and reflects the enterprising spirit of the library and implements the "reader-centered" service of the library Concept, to further enhance the library's position in the minds of readers.

\section{References}

[1] Chen Qin, Zhou Jianfang, Discussion on Application of MicroVideo in University Library Training Seminar, Journal of Library Science, vol. 04, pp. 88-93,2016 (04).

[2] Sha Yuping, Zhou Jianfang, Analysis of Micro-Video Service in University Library. Library Science Research ,vol. 19, pp.60-63,2015.

[3] Chen Yan, The Current Situation and Suggestions of Micro-Video Service in Domestic Academic Libraries-Based on the Research of "985 Project" University Library. Library Science Research ,vol.12,pp.21-25,2015. 
[4] Kuang Wenbo, What is new media in the end? News and writing,vol. 07, pp.24-27, 2012.

[5] Shaoqing Hai,New media definition analysis, China Broadcasting,vol.03,pp.60-63,2011.

[6] Liao Xiangzhong, What is the new media, Modern Communications,vol.5,pp.121-125, 2008.

[7] Xiong Chengyu. New media and cultural industries http://media.people.com.cn/GB/35928/36353/3160168.html, 2005.

[8] Xu Jian, Jiang Hong, Introduction to new media, 1st edition. Shanghai Jiaotong University Press, 2016. 